\title{
Predicting the Evolution of Sports Federation Membership: An Important Tool to Asses National Governing Bodies' Strategic Planning
}

\author{
Andreu Camps ${ }^{1}$ and Athanasios Sakis Pappous ${ }^{2}$ \\ Department of Sport Management, INEFC-University of Lleida, Lleida 25192, Spain \\ Department of Sport and Exercise Management, University of Kent, Canterbury, CT2 7NZ United Kingdom
}

\begin{abstract}
Quantifying the potential market of sports licenses is key in order for National Governing Bodies of sport (NGBs) to be able to design good strategic planning. We compared the classical methods of univariate prediction and the Autoregressive Integrated Moving Average (ARIMA) methods. Reliability of the available data was verified with the Time Series Regression with ARIMA Noise, Missing and Outliers (TRAMO) method, and the existence of a trend was verified using Daniel's test. For the purposes of this study - the researches collected and analysed secondary data from a 40-year series in 45 sports in Spain covering a very long period of time in a variety of sport disciplines. The study shows that, with the available data, short- and mid-term forecasting is possible in a number of sports, but not in all of them. It also proves that Holt's classical method of exponential smoothing is the one that yields best results. Golf, Basketball, Athletics and Hunting NGB show worrying prospects of decline levels and need an immediate change in the strategic plans. Other than for forecasting the evolution of athletes in the mid-term in order to improve strategic planning in NGBs, the present findings can be useful for public authorities to define their aid policies for NGBs, and they can also help companies in the industry to anticipate market developments.
\end{abstract}

Key words: Sports forecasting, ARIMA models, time series, market evolution.

\section{Introduction}

The aim of this study is to verify whether the application of various forecasting models to the time series data available for competitive sports yields positive prediction data in order to offer National Governing Bodies of sports (NGBs) and governments investing in competitive sport a diagnostic tool for the foreseeable development of competitive sport in a given period. Hopefully the outcome of this research will enables better strategic planning and better allocation of available public investment resources. As a further application, it could also be very useful to manufacturers of sports equipment and sports sponsors, since it provides reliable quantitative data on the evolution of the market (specifically for competitive sports) in the coming years.

Corresponding author: Andreu Camps Povill, Ph.D., professor, research field: sports management.
For those who work in the field of sports management the following questions are common and are still to be answered: Is it possible to predict the participation level in sports? How many athletes will be active club members of the Athletics NGB in 3-4 years? Will this sport exhibit an upward trend or will the number of participants decrease or stagnate? Will track and field and soccer or swimming exhibit similar quantitative trends? Will the sports on the Olympic schedule behave similarly to non-Olympic sports in the next few years in terms of the number of federated athletes? Will individual sports behave similarly to collective sports? Sports organizations must consider these questions in order to adapt their decisions to future objective and anticipated needs and to plan efficiently. Any coherent strategic plan requires information such as an estimate of future participants in a federation and the projected configuration of this 
federation [1-3].

A preliminary analysis of a considerable number of strategic plans of several sport competition entities (for example, Paralympic International Committee, Union Cycliste Internationale (UCI), International Powerlifting Federation (IPF), Cayman National Olympic Committee, Sports Australia, Australia and England Football Federation, and Sports Youth Organization) reveals that they maintain data from the past, present and future "sports objectives" (sport results, number of competitions, and anticipated television income). However, in their respective strategic plans, there is no evidence of any rigorous and methodologically sound prediction of the number of participants. In our literature review, we have observed a lack of academic and methodologically contrasted proposals that enable the measurement or formulation of predictive calculations of the behaviors of participants in a specific location, during a specific time period and for a specific sport and hopefully this study will contribute to cover this gap.

\section{Review of the Literature}

The study of sports in the context of social sciences has an extensive history. Areas of study such as psychology [4-5] and sociology [6-7] or modern approaches, such as economical [8-9] and sport markets [10] are valid examples of this dynamic. These areas of study utilize the following three approaches: competition in sports with its derivatives (organizational, professional, economic, legal, and social [11], sport as a recreation and utilitarian element (motivation, projection, and demand [2] — study compared based on the Europass), and physical education and physical culture (as a transmitter of values and rules for social behavior) [12].

The majority of these studies have focused on the behavior of sports throughout history from different perspectives: historicist [13-15], values of sport [6], analysis of the results of sporting events [16], participants [17], spectators/fans [18-20], evolution of organizations and their efficiency [21], industry and market [22-24] and events [25-26]. From a comprehensive analysis of the literature, we discovered that two time-based contexts predominate in these studies: the past and the present. Scientific studies related to sports focus on the present (with data that correspond to the present or extend from the past to the present) or they are based on data from the past. Some of the studies analyze sports with a focus on the future [27-28]. However, the majority of studies are based on qualitative methods [8, 13, 29, 30] and few of them approach the topic from a quantitative perspective [28, 31].

Several studies predict the number of spectators in a sporting event or in a sports centre based on the satisfaction of previous experiences or results based on the level of training of the athletes; some studies predict the number of medals or awards in a sports competition based on different elements, which are more qualitative than quantitative [32].

Diverse data obtained from time series have been frequently employed to predict, for example, teams that have the best chances of winning or the conditions that may improve their chances of winning a competition [33] based on data evaluation in a social context, which corresponds to the teams and relates the data to the results of that team or the probability that a team will win a soccer match in the British Premier League based on previous results [34] or in basketball $[35,36]$ or in ice hockey [37]. These data have also been employed to analyze the results of games played at home as an advantageous factor to win a match [38], to predict the sports results of a team/country in an event based on relevant data trends $[27,39,40]$ and to determine the probability of winning or achieving sports results based on the analysis of previous time series data in the same event or field position or using the same technique or tactic [41-44]. Studies conducted by Shoham and Rose [45] predict future consumption in sports and the impact on 
the future consumption of participants' perceptions about their benefits (health and sociability).

Our literature review included also studies that focus on the improvement or prediction of the improvement in the physical shape of athletes or youth based on data analyses or results obtained throughout a period of time, such as the stability of motor skills in physical education classes, which is based on a year of time series of different behaviors in students [46]. Some studies utilize time series data of motor skills in students [47] or predict the capacity of the youth of Poland to throw the javelin [48].

Other studies predict records or individual sports results based on the analysis of previous data [49-52].

The prediction of improvements is due to participation in sports and its influence on psychological health based on the ARIMA model [53].

More linked to the context of our study objective, some academic research has focused on perspectives of employment in sports [54], that predict that volunteers will subsequently become members of governing committees in sports organizations [55], or that utilize economic impact data to establish new strategies in a sporting event, such as Hoopfest $(3 \times 3)$ [56].

A common element in all studies was the use of a qualitative approach rather than a strictly quantitative approach, such as the use of either univariate or multivariate elements, e.g., the population and per capita income of a country to predict the number of medals in the Olympic Games [27] or the multivariate study of the offensive results in basketball [57].

However, if we focus our review of the literature on studies that are principally or exclusively based on quantitative data related to sports management, we can identify the area that relates sports with betting and lotteries that are based on the results of sport competitions, such as the area with the most studies of this type. The literature review indicates that this type of predictive study, which employs methods based on time series such as ARIMA, is common in sports betting. For example, to predict the behavior of sales in sports betting in China and Shanghai [58], Wu and Li [59] analyze monthly sales series in sports betting and predict the volume of sales in sports betting in same area. Similarly, Yang et al. [60] establishes a prediction of sports betting consumption in the province of Sichuan to improve future promotional strategies. Studies by Spann and Skiera [61] include a comparative analysis of diverse prediction methods in the betting market or the application of predictive methods (ARIMA) to evaluate time series data (1999-2001) in social networks or sports debate forums, such as Sport Unicycling [62].

The ARIMA methods have also been used to predict sports results for soccer teams in the British Premier League using multivariate models in studies by Yiannakis et al. [33] or Niina [63], which analyze the monthly consumption of sports in the Japanese population from January 1997 to December 2003 based on the Family Income and Expenditure Survey of Japan; it includes four study items: sports equipment (EQ), sports monthly tuition (MT), sports admission (AD), and sports facility charges (FC).

\section{Methods}

Analyses of time series data are appropriate when the series of data are correlated [64, 65] and exhibit predictive effectiveness in several scientific areas of study [66], which renders them extremely helpful for organizations when making strategic decisions [67] or in the context of marketing as related to market share, investments in new products or promotional campaigns [68].

The advantages of univariate methods for time series compared with other econometric methods of prediction can be summarized in [69]: (1) The performance of causal econometric models is more sensitive than the performance of different methodologies [70]; (2) The presence of different frequencies in the data can produce different and 
uneven conclusions [69]; (3) Causal econometric studies are based on the fact that the structure of the model remains constant over time, which is not compatible with sectors such as tourism or sports, which is subject to constant evolution [71]. Univariate methods for time series provide better and more reliable results for these types of circumstances.

Classical methods of analysis for time series possess the advantage of not involving excessive complexity in their use and calculation and possess the disadvantage of not allowing its application in more complex problems. The hypotheses or questions will always be less ambitious. They can be used to formulate short-term predictions but are less efficient or not efficient for making medium- or long-term predictions.

In this study, we aim to compare the classical methods with the ARIMA model based on moving average (MA) models, autoregressive (AR) models, (ARIMA) models and non-stationary models (ARIMA).

The ARIMA or Box-Jenkins methodology facilitates predictions without predetermined previous conditions. When a time series has been characterized by the subsequent joint probability distribution, predictions can be made easily and quickly at different moments and comparisons of the real data obtained with these predictions are also possible. However, the time series can only be applied when significant data and/or observations are available. Otherwise, unreliable long-term predictions may occur [72].

\section{Results of the Different Levels of Analysis of the National Governing Bodies memberships}

\subsection{Data Source (PHASE 0)}

Some countries maintain reliable statistical data on the number of athletes-globally and segmented - who have registered or possess a sport membership during a specific time period. Therefore, we can obtain significant data on affiliated sport practices (sport by sport) in corresponding institutional web publications that focus on sports or that are responsible for maintaining statistical data in Spain (CSD csd.gob.es; The Spanish National Institute of Statistics; ine.es) (series from 1940 to 2012), Italy (The Italian Institute of Statisticsculturaincifre.istat.it) (series from 1999 to 2009), France (The French Ministry of Sports; sports.gouv.fr) (series from the year 2000 to 2012), Portugal (The Portuguese National Institute of Statistics ine.pt) (series from 2008 to 2012) or longitudinal studies on the behavior of sports participation in the United States [73]. Because they manage complete and chronologically extensive records, we will use Spanish data from 1940 to 2012 as the basis for this study, with the possibility of expanding the approach to other countries in subsequent studies.

\subsection{Preliminary Analysis of the Validity or Reliability of the Time Series Data (PHASE 1)}

The first methodological problem that we encounter derives from the quality of the data due to the "validity" or "reliability" of the collected time series data. The data were collected by official public entities dedicated to national statistics.

There are still some that should be taken into account: (1) Extended time series with a high probability of changes in data collection criteria (may include regional athletes, trainers and referees); (2) Data that is provided individually by each federation without a supervising external agent; (3) Data that is conditioned by public contributions to the NGBs as a function of the number of memberships; (4) The new structure acquired by the Spanish state in 1980, which modified the legislative and organizational framework of sports in the NGB's; (5) Since 1980, active sport members can participate in NGBs assemblies, but only the data from the electoral year are considered for the census; (6) Specific actions of public assistance to a specific sport in a specific year or period; (7) Potential integration of new sport categories in a single sport 
federation; (8) Material and typographical errors in the data.

To overcome these limitations, we have employed the program Time Series Regression with ARIMA Noise, Missing Observations, and Outliers (TRAMO), which is based on an algorithm developed by [74] for the Bank of Spain, beginning with the first studies by Maravall and Peña [75]. This program has also been extensively used by the European Central Bank and by the majority of the Institutes of Statistics of European countries. The program's objective is to provide a specific methodology for a "preliminary review" of the time series based on ARIMA-type models.

Currently, the procedure of automatic identification of the TRAMO model and the complete signal extraction in ARIMA time series (SEATS) program have been adapted and incorporated by the U.S. Bureau of the Census to their new program X13-ARIMA-SEATS.

The Eurostat website also contains works related to TRAMO-SEATS. In this study, we reference the 2009 document ESS Guidelines on Seasonal Adjustment because it is relevant to harmonizing the European Statistics System.

Application of the TRAMO program enables adjustment and pre-adjustment of the series to be analyzed, without regard for missing values. A linearization process is performed on the series through the correction of outliers, and "seasonality" is eliminated whenever possible by selecting the ARIMA model that closely applies to the series being studied.

Once the model for validation and smoothing of the data is defined, we also determine the program or statistical package to be used in the study. We handle the available data in the time series using the Gretl statistical package (GNU Regression, Econometrics and Time-series Library) given its simplicity and accessibility and because it is a freely distributed and open code that is frequently employed to perform econometric calculations.

After the statistical analyses were performed and the problems detected in each of the series were resolved, the series was validated by a comparative analysis of the original data and the modified data, which was performed by a statistical analyst and a sports researcher to avoid errors and biases caused by over-refinement of the data.

Some examples of the application of the TRAMO program to the time series obtained from Spanish NGBs data.

We present comparative graphs (Figs. 1 and 2) that show the original data (dotted curve) and the results from application of the TRAMO program (solid curve)

\subsection{Classical Analysis of Time Series (PHASE 2)}

After the available series were analyzed regarding the presence of outliers and modulated using the TRAMO program, each of the series were analyzed using the classical time series methodology and a time

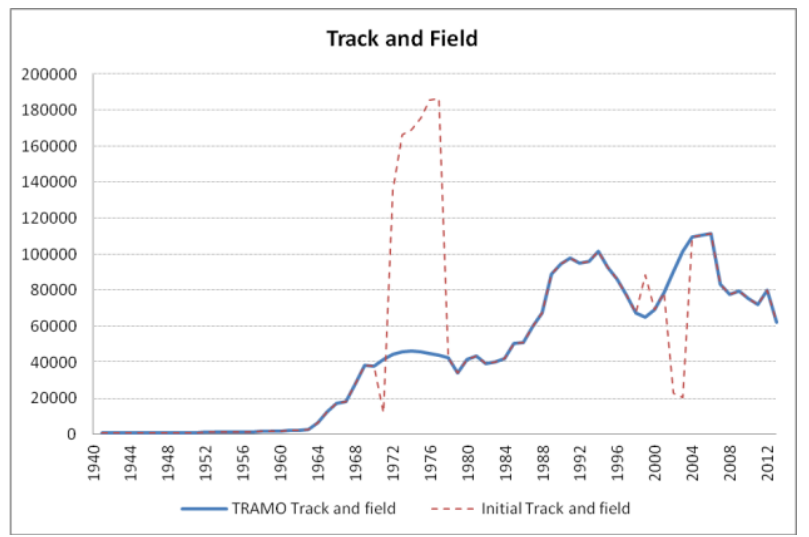

Fig. 1 Track and field.

Note: Significant outliers in certain periods

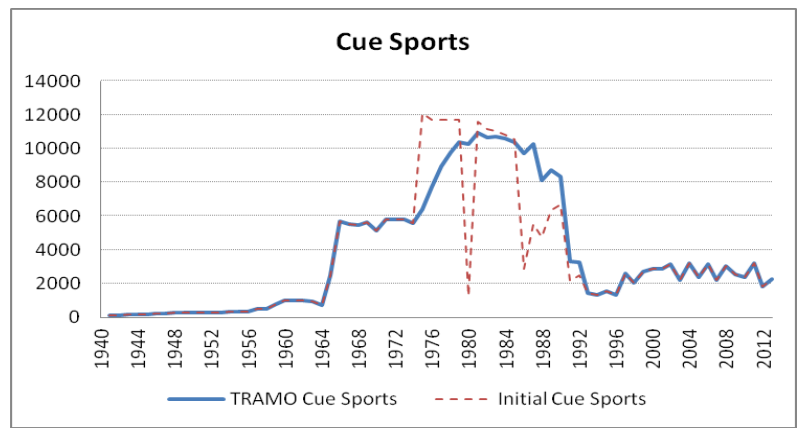

Fig. 2 Cue sports.

Note: Abundant and prolonged outliers 
series stochastic analysis (ARIMA or Box-Jenkins methodology).

To identify trends, we employed Daniel's Test. The null hypothesis of Daniel's Test is that a series does not exhibit a trend, whereas the alternative is that a trend exists. This bilateral nonparametric test is derived from the Spearman [76] range correlation and measures the correlation between the time range and the range of values.

Some examples of the application of Daniel's Test to the time series that corresponds to NGBs in Spain, see Table 1.

This type III series exhibits a trend and does not exhibit a seasonal component.

The data indicate that all absolute values are greater than 1.96 when Daniel's test is applied; this finding causes us to reject the null hypothesis due to the finding of a trend. We verify that a trend exists in all data.

However, all NGBs or sports being studied do not reflect a trend. We discovered that some time series for memberships that correspond to several different NGBs did not exhibit a trend because the null hypothesis could not be rejected (Karate, Sports dances, Water skiing).

Few time series that correspond to sports memberships for Spanish NGBs exhibit a negative trend (Squash, Taekwondo, Weightlifting).

\subsection{Prediction Analysis of the Time Series (PHASE 3)}

The methods used for prediction are as follows: (1) If the series does not exhibit a trend (type I series), we employed the following methods: Simple median method, Naive method, Moving median method (with different lengths), Simple exponential smoothing method (with different constants). (2) If the series exhibits a trend (type III series) we employed the following methods: Linear trend method, Double moving average method (with different lengths), Holt exponential smoothing method (with different constants).

Once the different classical methods have been applied, we proceeded to apply the ARIMA model or Box-Jenkins methodology to compare it with other classical models and evaluate which of the different models exhibits a better predictive capacity for the time series that corresponds to sports memberships in Spanish sports NGBs.

Based on these characteristics and restrictions, the ARIMA analysis can be performed using the Box-Jenkins methodology, the functional form of the stochastic process that generates the time series can be identified and its prediction can be achieved.

\subsection{Applying Descriptive and Predictive Methods to Existing Time Series (PHASE 4)}

The results of each of the applied methods (classical and ARIMA) have been used to calculate the “estimation” error ex-ante (mean squared error - MSE)

Considering

- If MAPE < 1\%, it exhibits a "very good" predictive capacity.

- If MAPE is between $1 \%$ and $3 \%$, it exhibits a "good" predictive capacity.

- If MAPE is between 3\% and 5\%, it exhibits "average" predictive capacity.

Table 1 Daniel's Test.

\begin{tabular}{llllllllll}
\hline & $\begin{array}{l}\text { Track and } \\
\text { field }\end{array}$ & Cycling & Tennis & Swimming & Soccer & Basketball & $\begin{array}{l}\text { Mountain } \\
\text { climbing }\end{array}$ & Car racing & Chess \\
\hline$\Sigma \mathrm{d}^{2}$ & 3666 & 2934 & 7172 & 1164 & 368 & 62 & 6192 & 2548 & 5218 \\
Observations (T) & 72 & 72 & 72 & 72 & 72 & 72 & 72 & 72 & 72 \\
Daniel's Test (Tau- $\tau)$ & 0.94 & 0.95 & 0.88 & 0.98 & 0.99 & 1.00 & 0.90 & 0.96 & 0.92 \\
Daniel's Test (Z) & 7.93 & 8.03 & 7.45 & 8.27 & 8.38 & 8.42 & 7.59 & 8.08 & 7.72 \\
\hline
\end{tabular}

Ho: No trend is identified.

Ha: A trend is identified.

Because $|\mathrm{Z}|>1.96$, the null hypothesis is rejected and a trend is confirmed. 
- If MAPE > 5\%, it exhibits a "poor or very poor" predictive capacity.

Examples of the applications of classical and ARIMA models in the time series that corresponds to sports NGBs in Spain, see Tables 2-5.

As expected, each of the time series exhibits a different predictive capacity.
4.6 Predicting the Evolution of Sports in Spain for the Period 2013-16 (PHASE 5) (Only for Sports for Which Predictive Ability Is Average, Good or Very Good).

Having identified the method that provides better predictive ability for each sport, we were able to estimate the quantitative change in the evolution of

Table 2 "Poor or very poor" predictive capacity.

\begin{tabular}{llllllll}
\hline & $\begin{array}{l}\text { Track and } \\
\text { field }\end{array}$ & Cue sports & Car racing & Squash & Karate & Table tennis Taekwondo \\
\cline { 2 - 7 } & MAPE & MAPE & MAPE & MAPE & MAPE & MAPE & MAPE \\
\hline Linear Trend & $36.3 \%$ & $164.4 \%$ & $10.1 \%$ & $70.9 \%$ & $14.4 \%$ & $12.6 \%$ & $15.4 \%$ \\
Double Moving Average $-\mathrm{K}=2$ & $6.3 \%$ & $23.4 \%$ & $8.6 \%$ & $36.7 \%$ & $7.8 \%$ & $31.7 \%$ & $12.7 \%$ \\
Double Moving Average $-\mathrm{K}=3$ & $14.7 \%$ & $30.7 \%$ & $19.1 \%$ & $31.1 \%$ & $7.7 \%$ & $30.5 \%$ & $13.4 \%$ \\
Double Moving Average $-\mathrm{K}=4$ & $28.5 \%$ & $26.1 \%$ & $32.8 \%$ & $21.4 \%$ & $7.6 \%$ & $10.0 \%$ & $14.6 \%$ \\
Double Moving Average $-\mathrm{K}=5$ & $13.3 \%$ & $30.9 \%$ & $27.7 \%$ & $19.5 \%$ & $7.3 \%$ & $8.6 \%$ & $13.1 \%$ \\
Double Moving Average $-\mathrm{K}=6$ & $7.5 \%$ & $28.4 \%$ & $21.5 \%$ & $18.3 \%$ & $7.2 \%$ & $16.8 \%$ & $11.9 \%$ \\
Holt Exp. Smoothing & $6.1 \%$ & $21.1 \%$ & $9.4 \%$ & $12.0 \%$ & $7.4 \%$ & $5.4 \%$ & $11.2 \%$ \\
ARIMA & $8.0 \%$ & $38.4 \%$ & $30.0 \%$ & $24.5 \%$ & $9.0 \%$ & $11.8 \%$ & $12.4 \%$ \\
\hline
\end{tabular}

Table 3 "Average" predictive capacity.

\begin{tabular}{llllll}
\hline & Skeet shooting & Motorcycling & Archery & Golf & Equestrian \\
\cline { 2 - 6 } & MAPE & MAPE & MAPE & MAPE & MAPE \\
\hline Linear Trend & $67.4 \%$ & $4.6 \%$ & $12.6 \%$ & $36.4 \%$ & $55.1 \%$ \\
Double Moving Average $-\mathrm{K}=2$ & $9.4 \%$ & $8.4 \%$ & $5.6 \%$ & $5.3 \%$ & $8.1 \%$ \\
Double Moving Average $-\mathrm{K}=3$ & $7.9 \%$ & $29.5 \%$ & $8.0 \%$ & $12.7 \%$ & $8.3 \%$ \\
Double Moving Average $-\mathrm{K}=4$ & $13.9 \%$ & $39.1 \%$ & $6.5 \%$ & $17.1 \%$ & $5.1 \%$ \\
Double Moving Average $-\mathrm{K}=5$ & $19.1 \%$ & $43.1 \%$ & $5.4 \%$ & $16.2 \%$ & $4.7 \%$ \\
Double Moving Average $-\mathrm{K}=6$ & $18.4 \%$ & $50.0 \%$ & $5.4 \%$ & $18.2 \%$ & $4.9 \%$ \\
Holt Exp. Smoothing & $4.5 \%$ & $4.6 \%$ & $3.7 \%$ & $3.3 \%$ & $3.6 \%$ \\
ARIMA & $20.5 \%$ & $50.8 \%$ & $5.1 \%$ & $30.4 \%$ & $16.5 \%$ \\
\hline
\end{tabular}

Table 4 "Good" predictive capacity.

\begin{tabular}{lllllll}
\hline & Tennis & Swimming & Badminton & Volleyball & Gymnastics & Triathlon \\
\cline { 2 - 7 } & MAPE & MAPE & MAPE & MAPE & MAPE & MAPE \\
\hline Linear Trend & $17.7 \%$ & $17.1 \%$ & $7.4 \%$ & $12.9 \%$ & $48.3 \%$ & $34.5 \%$ \\
Double Moving Average $-\mathrm{K}=2$ & $4.0 \%$ & $6.3 \%$ & $2.3 \%$ & $2.0 \%$ & $39.5 \%$ & $4.7 \%$ \\
Double Moving Average $-\mathrm{K}=3$ & $5.6 \%$ & $10.1 \%$ & $9.8 \%$ & $8.2 \%$ & $7.6 \%$ & $8.3 \%$ \\
Double Moving Average $-\mathrm{K}=4$ & $8.7 \%$ & $2.9 \%$ & $9.6 \%$ & $10.1 \%$ & $16.1 \%$ & $10.0 \%$ \\
Double Moving Average $-\mathrm{K}=5$ & $10.3 \%$ & $2.4 \%$ & $8.4 \%$ & $13.3 \%$ & $25.0 \%$ & $12.5 \%$ \\
Double Moving Average $-\mathrm{K}=6$ & $10.8 \%$ & $2.5 \%$ & $7.5 \%$ & $12.0 \%$ & $27.6 \%$ & $16.0 \%$ \\
Holt Exp. Smoothing & $2.8 \%$ & $1.5 \%$ & $2.0 \%$ & $1.5 \%$ & $1.3 \%$ & $1.5 \%$ \\
ARIMA & $4.8 \%$ & $12.1 \%$ & $4.6 \%$ & $26.2 \%$ & $23.7 \%$ & $3.1 \%$ \\
\hline
\end{tabular}


Table 5 "Very good" predictive capacity.

\begin{tabular}{|c|c|c|c|c|c|c|c|c|}
\hline & Cycling & Soccer & Basketball & $\begin{array}{l}\text { Mountain } \\
\text { climbing }\end{array}$ & Chess & Judo & Rowing & Handball \\
\hline & MAPE & MAPE & MAPE & MAPE & MAPE & MAPE & MAPE & MAPE \\
\hline Linear Trend & $14.8 \%$ & $16.5 \%$ & $22.8 \%$ & $34.1 \%$ & $20.7 \%$ & $25.5 \%$ & $0.7 \%$ & $12.7 \%$ \\
\hline Double Moving Average $-K=2$ & $1.8 \%$ & $2.7 \%$ & $5.5 \%$ & $2.9 \%$ & $1.3 \%$ & $0.9 \%$ & $3.2 \%$ & $1.1 \%$ \\
\hline Double Moving Average $-\mathrm{K}=3$ & $19.1 \%$ & $0.6 \%$ & $7.0 \%$ & $2.3 \%$ & $5.7 \%$ & $1.7 \%$ & $2.5 \%$ & $0.7 \%$ \\
\hline Double Moving Average $-K=4$ & $4.5 \%$ & $0.5 \%$ & $6.5 \%$ & $5.3 \%$ & $10.8 \%$ & $1.6 \%$ & $3.1 \%$ & $0.5 \%$ \\
\hline Double Moving Average $-K=5$ & $12.8 \%$ & $2.0 \%$ & $4.0 \%$ & $5.8 \%$ & $13.0 \%$ & $1.7 \%$ & $5.6 \%$ & $1.5 \%$ \\
\hline Double Moving Average $-K=6$ & $11.8 \%$ & $2.8 \%$ & $1.5 \%$ & $5.2 \%$ & $8.1 \%$ & $2.1 \%$ & $8.2 \%$ & $3.4 \%$ \\
\hline Holt Exp. Smoothing & $0.3 \%$ & $0.1 \%$ & $0.9 \%$ & $0.3 \%$ & $0.3 \%$ & $0.3 \%$ & $0.3 \%$ & $0.1 \%$ \\
\hline ARIMA & $2.7 \%$ & $3.4 \%$ & $12.2 \%$ & $3.1 \%$ & $6.9 \%$ & $20.2 \%$ & $12.1 \%$ & $7.6 \%$ \\
\hline
\end{tabular}

Table 6 Olympic vs. non Olympic.

\begin{tabular}{|c|c|c|c|c|c|}
\hline \multicolumn{3}{|c|}{ Summer Olympic sports } & \multicolumn{3}{|c|}{ Non Olympic sports } \\
\hline & Relat $\%$ & Absolute & & Relat \% & Absolute \\
\hline Soccer & $6.5 \%$ & 55396.1 & Mountaineening and climbing & $19.5 \%$ & 33030.5 \\
\hline Gymnastics & $37.3 \%$ & 11492.3 & Paddle & $30.0 \%$ & 12998.3 \\
\hline Equestrian & $23.7 \%$ & 11351.1 & Roller sports & $11.9 \%$ & 5358.7 \\
\hline Cycling & $15.8 \%$ & 10329.4 & Orienteering & $19.0 \%$ & 3604.0 \\
\hline Triathlon & $37.5 \%$ & 9101.0 & Motorcycle Racing & $3.4 \%$ & 605.9 \\
\hline Aquatics & $10.4 \%$ & 6372.8 & Dance sport & $7.0 \%$ & 157.0 \\
\hline Rugby & $25.9 \%$ & 6165.3 & Chess & $-3.7 \%$ & -810.5 \\
\hline Sailing & $16.0 \%$ & 5571.3 & Football & $-61.6 \%$ & -2747.8 \\
\hline Hockey & $22.1 \%$ & 2627.7 & Bowling & $-60.8 \%$ & -4197.8 \\
\hline Rowing & $4.7 \%$ & 491.8 & Underwater sports & $-25.3 \%$ & -8023.9 \\
\hline Badminton & $5.0 \%$ & 338.5 & Fishing \& casting & $-28.7 \%$ & -16348.3 \\
\hline Modern Pentathlon & $-52.5 \%$ & -86.1 & Hunting & $-9.9 \%$ & -34675.1 \\
\hline Canoe & $-3.8 \%$ & -240.7 & & & \\
\hline Boxing & $-11.3 \%$ & -339.8 & & & \\
\hline Handball & $-2.4 \%$ & -2173.0 & & & \\
\hline Judo & $-2.4 \%$ & -2581.5 & & & \\
\hline Tennis & $-3.0 \%$ & -2699.4 & & & \\
\hline Volleyball & $-8.1 \%$ & -4191.6 & & & \\
\hline Fencing & $-98.4 \%$ & -6047.6 & & & \\
\hline Shooting & $-17.4 \%$ & -9693.8 & & & \\
\hline Archery & $-132.4 \%$ & -9725.3 & & & \\
\hline Basketball & $-4.0 \%$ & -16019.9 & & & \\
\hline Golf & $-17.3 \%$ & -51159.4 & & & \\
\hline
\end{tabular}

sports for the next three years (until the Olympic Games Rio 2016), both in absolute and in relative (percentage) terms. The results are presented in Table 6.

\section{Discussion and Conclusions}

After applying the set of classical methods and ARIMA to the time series of sports memberships data in Spain between 1940 and 2012, we confirm that the classical method "Holt exponential smoothing" offers the best predictive results for short- and medium-term behaviors of sport memberships in Spain in nearly all cases.

From a strictly methodological point of view, we must conclude that the quality of the information directly affects the results when the goal is to obtain a joint probabilistic distribution, such as for the ARIMA method. Based on the general theory on time series 
[77], ARIMA performs well when series of more than 40-50 time-based observations are available (the case of this study) because this large number of observations can be used to refine the stochastic process in which the series are distributed. If we consider the general theory on time series, we should have obtained better results with the ARIMA methodology than with the classical methods $[64,77$, 78]. However, our study reveals opposite results. What could have happened? How can these results be explained?

From our point of view, the explanation is simple because the general theory does not state that an extensive time series (+ 40-50 data) is sufficient for analyzing the ARIMA method. In addition, the data must be collected using a single standard method because use of different data collection criteria every year or every several years will cause the ARIMA method to become inefficient, which occurs in the time series for sports memberships. A problem with the original time series is the disparity of the criteria and methods (in a single series) that were used to gather the information and the criteria to introduce specific sports memberships (scholar, promotional, competition only, state only, and state + automatic). This situation is the main reason that the ARIMA method does not provide satisfactory predictive results compared with the classical methods, given that the latter are less sensitive to this factor [77].

The study has empirically demonstrated that ARIMA does not yield accurate predictions with these assumptions, whereas the classical methodology provides satisfactory predictions due to the considerable differences in data collection, which are not dependent on "normal" factors, such as population growth or increases in economical or educational levels. They are dependent on important deterministic factors, such as the need for additional assistance or specific electoral results for a specific time period, which can affect the behavior of the data.

Although we were able to mitigate "evident" problems using the TRAMO program, an implicit problem that affects the ARIMA methodology exists given that it is not possible to find a more optimal regular pattern (the stochastic process and the joint distribution of data) compared with classical methodology estimations. ARIMA requires that the data show a certain degree of "stability" to detect a "pattern", but the method is not useful if nonprobabilistic changes occur every 3,4 , and 5 years [77]. In these types of studies, the methodological conclusion is of regardless of how refined the statistical techniques are, if the data are poor or do not reflect reality, the final results will be affected.

Therefore, the employed methods also help us attain another important conclusion, which "confirms" that the data from many NGBs are not reliable for specific periods of the sport license series. Since 2000, the Superior Council on Sports and the entities responsible for these issues introduced a rigorous rule to standardize data collection and publication of sports memberships for NGBs based on discrepancies in the data due to different factors (federation, autonomous communities, and sports insurance). We formulate the hypothesis that the ARIMA method performs better than classical methods for extended time series (2030-2040) with no significant variations in the criteria, it is very probable that at that time.

Conversely, we confirmed that the classical methodology appropriately adjusts to short-term changes, the Holt's method provides optimal results, and the double moving average method also performs well. This finding can be attributed to the notion that the methods consider the trend to be locally linear, that is, they estimate a trend for each year, which enables the methods to obtain better results (better refinement) for short-term changes (in our case, these changes comprised changes in structural, electoral, and deterministic criteria); this is the objective of this study.

From the point of view of the dynamics and behavior of federated competition sports in Spain, we 
can conclude that the first set of NGBs exhibits sports membership time series data with a very good predictive capacity (soccer, judo, cycling, basketball, rowing, handball, paddle, mountain climbing, chess, sports dances, etc.); the second set of NGBs exhibits good predictive capacity (badminton, sailing, modern pentathlon, boxing, volleyball, gymnastics, swimming, tennis, hockey, triathlon, bowling, hunting, fishing, speleology, rugby, etc.); the third set of NGBs exhibits average predictive capacity (equestrianism, archery, American football, golf, orienting, shooting, motorcycling, roller, etc.); and the last set of NGBs exhibits sports license series with poor or very poor predictive capacity (track and field, surfing, weightlifting, taekwondo, Olympic wrestling, table tennis, car racing, cue sports, water skiing, karate, boules, squash, rescue and lifesaving, etc.). The number of NGBs that exhibit poor or average predictive capacity is greater than the number of NGBs that exhibit good or very good predictive capacity. However, if we relate these results with the total number of club members, we discover that "large" NGBs (federations with the largest number of club members) exhibit better results concerning predictive capacity.

Based on these conclusions, we can and should state that each data, variable or series (in our case, each sport) requires specific estimation technique and that the more refined techniques, a priori (ARIMA, for example), do not have to be the best techniques in all cases given that the best technique can optimally adapt to the structure of the available information.

In general terms, non-Olympic sports show higher predicted growth rates than Olympic sports. For all sports, the rates of absolute and relative increase in club members for the next three years are very low. Soccer and mountaineering have a good growth prospects. Golf, basketball, athletics and hunting show worrying levels of decline. These NGBs need of an immediate change in the strategic plans.

This study has enabled us to verify that we can provide sports NGBs and competent public entities with a reliable method to predict the short- and medium-term future behaviors of sports memberships for sport NGB's, which can be useful for their strategic planning or public investment decisions. Other than forecasting the evolution of athletes in the mid-term in order to improve strategic planning in NGBs, the present findings can be useful for public authorities to define their funding policies for NGBs, and they can also be useful for companies in the industry to anticipate market developments.

\section{References}

[1] Emery, P. 2010. "Past, Present, Future Major Sport Event Management Practice: The Practitioner Perspective." Sports Management Review 13 (2): 158-70.

[2] Ruseki, J., and Maresova, K. 2013. "Economic Freedom, Sport Policy, and Individual Participation in Physical Activity: An International Comparison." Contemporary Economic Policy 32 (1): 42-55.

[3] Theodorakis, N., Alexandris, K., Tsigilis, N., and Karvounis, S. 2013. "Predicting Spectators Behavioural Intentions in Professional Football: The Role of Satisfaction and Service Quality." Sports Management Review 16 (1): 85-96.

[4] Cole, B. 2013. "Sport Psychology: A Short History and Overview of a Field Whose Time Has Come, and How It Can Help You in Your Sport.” Accessed April 4, 2013. http://www.mentalgamecoach.com/articles/SportPsychol ogy.html.

[5] Green, B. C., and Costa, C. A. 2007. "Sport Consumer Behavior." In Contemporany Sport Management, edited by Parks, J., Quarterman, J., and Thibault, L. Champaign: Human Kinetics, 219-42.

[6] Dunning, E., ed. 1999. Sport Matters: Sociological Studies of Sport, Violence and Civilization. Abingdon: Routledge.

[7] Weed, M. 2005. "Research Synthesis in Sport Management: Dealing with "Chaos in the Brickyard"." European Sport Management Quarterly 5 (1): 77-90.

[8] Andreff, W., and Szymanski, S., ed. 2006. Handbook on the Economics of Sport. Glos: Edward Elgar.

[9] Downward, P., Dawson, A., and Dejonghe, T. 2009. Sports Economics. Theory, Evidence and Policy. Oxford: Elsevier.

[10] Kahn, L. 2000. “The Sports Business as a Labor Market Laboratory." The Journal of Economic Perspectives 14 (3): 75-94. 


\section{Asses National Governing Bodies' Strategic Planning}

[11] Slack, T. 1994. "Theoretical Diversity and the Study of Sport Organizations." International Review for the Sociology of Sport 29 (3): 239-42.

[12] Cagigal, J. M. 1975. The Sport in Current Society. Madrid: Editora Nacional. (in Spanish)

[13] Augustin, J. P. 2007. Geography of Sport: Contemporary Spatiality and Globalization. Paris: Armand Colin. (in French)

[14] Huizinga, J. 1972. 1938. Homo Ludens. Madrid: Alianza Editorial.

[15] Miller, T., Laurence, G., Mckay, J., and Rowe, D. 2001. Globalization and Sport. Playing the World. London: Sage.

[16] Morton, R. H. 2002. "Who Won the Sydney Olympics? An Allometric Approach." Journal of the Royal Statistical Society: Series D: (The Statistician) 51 (2): 147-55.

[17] Lim, S. Y., Warner, S., Dixon, M., Berg, B., Kim, Ch., and Newhouse-Bailey, M. 2011. "Sport Participation across National Contexts: A Multilevel Investigation of Individual and Systemic Influences on Adult Sport Participation." European Sport Management Quarterly 11 (3): 197-224.

[18] Crawford, G. 2004. Consuming sports: Fans, Sport and Culture. Abington: Routledge.

[19] Funk, D., Beaton, A., and Alexandris, K. 2012. "Sport Consumer Motivation: Autonomy and Control Orientations that Regulate Fan Behaviours." Sports Management Review 15 (3): 355-67.

[20] Mahony, D., and Moorman, A. 1999. "The Impact of Fan Attitudes on Intention to Watch Professional Basketball Team on Television." Sports Management Review 2 (1): 43-66.

[21] Slack, T., and Parent, M. 2006. Understanding Sport Organization. The Application of Organization Theory. Champaign: Human Kinetics.

[22] Drayer, J., Rasher, D. A., and McEvoy, C. D. 2012. “An Examination of Underlying Consumer Demand and Sport Pricing Using Secondary Market Data." Sports Management Review 15 (4): 448-60.

[23] VanLeeuwen, L., Quick, S., and Daniel, K. 2002. "The Sport Spectator Satisfaction Model: A Conceptual Framework for Understanding the Satisfaction of Spectators." Sports Management Review 5 (2): 99-128.

[24] Wicker, P., Prinz, J., and von Hanau, T. 2012. "Estimating the Value of National Sporting Success." Sports Management Review 15 (2): 200-10.

[25] Burgan, B., and Mules, T. 1992. "Economic Impact of Sporting Events." Annals of Tourism Research 19 (4): 700-10.

[26] Horne, J., and Manzenreiter, W. 2004. "Accounting for Mega-Events: Forecast and Actual Impacts of the 2002
Football World Cup Finals on the Host Countries Japan/Korea." International Review for the Sociology of Sport 39 (2): 187-203.

[27] Bernard, A., and Busse, M. 2004. "Who Wins the Olympic Games: Economics Resources and Medals Total." The Review of Economics and Statistics 86 (1): 413-7.

[28] Bohlmann, H. R., and Van Heerden, J. M. 2008. "Predicting the Economic Impact of the 2010 FIFA World Cup on South Africa." International Journal of Sport Management and Marketing 3 (4): 383-96.

[29] Fasting, K. 1982. "A Prediction Model for Participation in Sport." International Review for the Sociology of Sport 17 (3): 29-39.

[30] Harville, D. 1980. "Predictions for National Football League Games with Linear-model Methodology." Journal of the American Statistical Association 75 (371): 516-24.

[31] Butenko, S., Lafuente, J., and Pardalos, P., ed. 2010. Optimal Strategies in Sports Economics and Management. Heidelberg: Springer.

[32] Brouwers, J., De Bosscher, V., and Sotiriadou, P. 2012. "An Examination of the Importance of Performances in Youth and Junior Competition as an Indicator of Later Success in Tennis." Sports Management Review 15 (4): 461-75.

[33] Yiannakis, A., Selby, M. J. P., Douvis, J., and Han, J. Y. 2006. "Forecasting in Sport. The Power of Social context-A Time Series Analysis with English Premier League Soccer." International Review for the Sociology of Sport 41 (1): 89-115.

[34] Stern, H. 1991. "On the Probability of Winning a Football Game." The American Statistician 45 (3): 179-83.

[35] Lopez, M., and Matthews, G. 2015. "Building an NCAA Men's Basketball Predictive Model and Quantifying its Success." Journal of Quantitative Analysis in Sports 11 (1): 5-12.

[36] Ruiz, F., and Perez-Cruz, F. 2015. "A Generative Model for Predicting Outcomes in College Basketball." Journal of Quantitative Analysis in Sports 11 (1): 39-52.

[37] Brockwell, P. J., and Davis, R. A. 1991. Time Series: Theory and Methods. New York: Springer-Verlag.

[38] Pollard, R., and Pollard, G. 2005. "Long-term Trends in Home Advantage in Professional Team Sports in North America and England (1876-2003)." Journal of Sports Sciences 23 (4): 337-50.

[39] Drever, P., and Mcdonald, J. 1981. "Attendances at South Australian Football Games." International Review for the Sociology of Sport 16 (2): 103-13.

[40] Vanegas, G., and Vlachokyriakou, E. 2012. "Olympic Medals and Demo-economic Factors: Novel Predictors; the Ex-host Effect, the Exact Role of Team Size; and the 
"Population-GDP" Model Revisited." Sports Management Review 15 (2): 211-7.

[41] Baghal, T. 2012. "Are the "Four Factors" Indicators of One Factor? An Application of Structural Equation Modeling Methodology to NBA Data in Prediction of Winning Percentage." Journal of Quantitative Analysis in Sport 8 (1).

[42] Koulis, Th., Muthukumorana, S., and Brïercliffe, C. D. 2014. "A Bayesian Stochastic Model for Batting Performance Evaluation in One-day Cricket." Journal of Quantitative Analysis in Sport 10 (1): 1-13.

[43] Sánchez, J. M., Castellanos, P., and Dopico, J. 2007. "The Winning Production Function: Empirical Evidence from Spanish Basketball." European Sport Management Quarterly 7 (3): 283-300.

[44] Stekler, H., and Klein, A. 2012. "Predicting the Outcomes of NCAA Basketball Championship Games." Journal of Quantitative Analysis in Sport 8 (1).

[45] Shoham, A., and Rose, G. M. 2000. "Predicting Future Sport Consumption. The Impact of Perceived Benefits." Sport Marketing Quarterly 9 (1): 8-14.

[46] Schempp, P. 1987. "Behavioral Stability in Physical Education: A One-year Time Series Analysis." Research Quarterly for Exercise and Sport 58 (4): 382-7.

[47] Blackwell, J., Simmons, R., and Spay, J. 1991. "Time Series Analysis of Knowledge of Results Effects During Motor Skill Acquisition." Research Quarterly for Exercise and Sport 62 (1): 10-7.

[48] Maszczyk, A., Roczniok, R., Pietraszewski, P., Stanula, A., Zajac, A., and Golas, A. 2012. "Time Series Approach To Athletes Motor Potential." Polish Journal of Sport and Tourism 19 (2): 103-6.

[49] Heiny, E., and Heiny, R. 2014. "Stochastic Model of the 2012 PGA Tour Season." Journal of Quantitative Analysis in Sports 10 (4): 367-79.

[50] Lebovic, J. H., and Sigelman, L. 2001. "The Forecasting Accuracy and Determinants of Football Rankings." International Journal of Forecasting 17 (1): 105-20.

[51] Mulholland, J., and Jensen, Sh. 2014. "Predicting the Draft and Career Success of Tight Ends in the National Football League." Journal of Quantitative Analysis in Sports 10 (4): 381-96.

[52] Volj, P. 2011. "A Stochastic Model of Progression of Athletic Records." IMA Journal of Management Mathematics 22 (2): 157-69.

[53] Li, M., Deng,Y., Yu, R., Zhang, J., and Wen, H. 2013. "Time Series Analysis of Sports Activity's. Influence on Phychological Health Based on ARIMA Model." International Journal of Applied Mathematics and Statistics 45 (15): 272-9.

[54] Quain, R. J., and Parks, J. B. 1986. "Sport Management Survey: Employment Perspectives.” Journal of Physical
Education, Recreation and Dance 57 (4): 18-21.

[55] Cuskelly, G., and Boag, A. 2001. "Organizational Commitment as a Predictor of Committee Member Turnover among Volunteer Sport Administration: Results of a Time-lagged Study." Sports Management Review 4 (1): 65-86.

[56] Bozman, C. S., Kurpis, L., and Frye, Ch. 2010. "Hoopfest: Using Longitudinal Economic Impact Data to Assess the Success of a Strategic Reorientation." Sports Management Review 13 (1): 65-81.

[57] Kaplan, D. 2008. "Univariate and Multivariate Autoregressive Time Series Models of Offensive Baseball Performance: 1901-2005." Journal of Quantitative Analysis in Sport 4 (3).

[58] Li, G. 2013. "The Determinants of per Capita Sales of Lottery and the Forecast on the Developing Trend of the Lottery Market in China. China Sport Science, 2006-12." Accessed January 2, 2013. http://en.cnki.com.cn/Article_en/CJFDTOTAL-TYKX20 0612006.htm.

[59] Wu, Y., and Li, H. 2013. "Sales Volume Prediction of the Sports Lottery Based on ARIMA. Taking Shanghai as an Example.” Sport Science Research 05. Accessed March 14,

2013. http://en.cnki.com.cn/Article_en/CJFDTOTAL-TYKA20 1305007.htm.

[60] Yang, Y., Cheng, L., and Zgao, Y. 2012. "Measurement Model of Sports Lottery Sales Volume and the Concerning Promotion Strategy-A Case of Sichuan Province." Journal of Chengdu Sport University 2009-12. Accessed March 14, 2013. http://en.cnki.com.cn/Article_en/CJFDTOTAL-SORT201 209002.htm.

[61] Spann, M., and Skiera, B. 2009. "Sport Forecasting: A Comparison of the Forecast Accuracy of Prediction Markets Betting Odds and Tipsters." Journal of Forecasting 28 (1): 55-72.

[62] Erhardt, E. 2002. "Box-Jenkings Metodology vs Rec.Sport.Unicycling 1999-2001.” Accessed April 15, 2013.

http://statacumen.com/pub/proj/WPI/Erhardt_Erik_tsapro j.pdf.

[63] Niina, K. 2004. "Time Series Analysis of the Consumer Expenditure on Sport in Japan." Accessed November 5, 2012.

http://easm.net/download/2004/5e20857416ed1ddcb664a ab8bbc27be9.pdf.

[64] Box, G. E. P., Jenkins, G. M., and Reinsel, G. C. 1994. Time Series Analysis: Forecasting and Control. Englewood Cliffs: Prentice Hall.

[65] Du Perez, J., and Witt, S. 2003. "Univariate versus Multivariate Time Series Forecasting: An Application to 
International Tourism Demand." International Journal of Forecasting 19 (3): 435-51.

[66] Zou, H., and Yang, Y. 2004. "Combining Time Series Models for Forecasting." International Journal of Forecasting 20 (1): 69-84.

[67] Makridakis, S. 1996. "Forecasting: Its Role and Value for Planning and Strategy." International Journal of Forecasting 12 (4): 513-37.

[68] Kahn, K., and Mentzer, J. 1995. "Forescasting in Consumer and Industrial Markets." The Journal of Business Forecasting 14 (2): 21-8.

[69] Song, H., Witt, S., and Jensen, T. 2003. "Tourism Forecasting: Accuracy of Alternative Econometric Models." International Journal of Forecasting 19 (1): 123-41.

[70] Lim, C., and McAleer, M. 2001. “Time Series Forecasts of International Tourism Demand for Australia, Osaka University, The Institute of Social and Economic Research.” Accessed April 21, 2013. http://www.iser.osaka-u.ac.jp/library/dp/2001/dp0533.pdf.

[71] Lise, W., and Tol, R. 2000. "Impact of Climate on Tourism Demand." Accessed April 25, 2013. http://www.fnu.zmaw.de/fileadmin/fnu-files/publication/ working-papers/Tourismpaper.PDF.

[72] Helmer, R., and Johansson, J. 1977. "An Exposition of the Box-Jenkins Transfer Function Analysis with an
Application to the Advertising-Sales Relationship." Journal of Marketing Research 14 (2): 227-39.

[73] Acosta, R.V., and Carpenter, L. J. 2012. "Women Intercollegiate Sport-A Longitudinal, National Study: Thirty Five Year Update 1977-2012." Accessed October 25 , 2013. http://acostacarpenter.org/AcostaCarpenter2012.pdf.

[74] Gómez, V., Maravall, A., and Peña, D. 1997. "Missing Observations in ARIMA Models: Skippings Strategy versus Additive Outlier Approach." Accessed March 6, 2013.

http://www.bde.es/f/webbde/SES/Secciones/Publicacione s/PublicacionesSeriadas/DocumentosTrabajo/97/Fic/dt97 01e.pdf

[75] Maravall, A., and Peña, D. 1996. "Missing Observations and Additive Outliers in Time Series Models." Documento de trabajo $n^{o}$ 9612, Servicio de Estudios, Banco de España. Accessed February 5, 2013. http://www.bde.es/f/webbde/SES/Secciones/Publicacione s/PublicacionesSeriadas/DocumentosTrabajo/96/Fich/dt9 612e.pdf.

[76] Spearman, C. 1904. "The Proof and Measurement of Association between Two Things." The American Journal of Psychology 15 (1): 72-101.

[77] Chatfield, C. 1989. The Analysis of Time Series: An Introduction. London: Champman and Hall. 